\title{
Extração de zeína e sua aplicação na conservação dos alimentos
}

\author{
Extraction of zein and its application in food preservation
}

\author{
Índira da Silva Papalia ${ }^{\mathrm{I}}$ Patrícia Medianeira Grigoletto Londero ${ }^{\mathrm{I}^{*}}$
}

\section{- REVISÃO BIBLIOGRÁFICA -}

\section{RESUMO}

\begin{abstract}
As proteinas do endosperma dos grãos de milho, referente às zeinas, apresentam grau de polimerização importante para formação de filmes em alimentos, sendo útil na conservação destes. Nesta revisão, serão abordadas formas de extração destas proteinas, através da solubilidade de seus aminoácidos em solventes alcoolicos e métodos combinados dos tratamentos químicos e enzimáticos. O polímero de zeína pode substituir polímeros sintéticos empregados em embalagens para alimentos, atribuindo valor econômico para a indústria do milho. Sua aplicação em filmes proporciona características funcionais de estabilidade de massa, controle microbiano e redução da oxidação lipídica em determinados alimentos, durante o seu armazenamento.

Palavras-chave: Zea mays, extração de zeina, filme, conservação dos alimentos.
\end{abstract}

\section{ABSTRACT}

The proteins of the endosperm of corn, referring to zein, have important degree of polymerization for the formation of the films on food, being useful in the conservation of it. This review will address ways of extracting these proteins by their amino acid solubility in alcoholic solvents and methods of combined chemical and enzymatic treatments. The polymer of zein can replace synthetic polymers used in food packaging, it contributes for economic value to the corn industry. Its application in films provides functional characteristics of mass stability, microbial control and reduction of lipid oxidation in some kind of food during storage.

Key words: Zea mays, extraction of zein, film, food preservation.

\section{INTRODUÇÃO}

A indústria do milho tem grande importância econômica devido à ampla distribuição de seu cultivo a nível mundial. Apesar da disponibilidade dos grãos de milho, suas proteínas caracterizam-se por serem pobres em aminoácidos lisina e triptofano, que são essenciais a nutrição, sendo $70 \%$ da produção destinada à alimentação animal, porém de baixo consumo humano (PAES, 2006; MIRANDA et al., 2012).

A aplicação da proteína do milho, referente à zeína, agrega valores pouco conhecidos e explorados a este cereal. Zeína é o nome específico de uma das proteínas derivadas do endosperma dos grãos de milho, classificada do grupo das prolaminas, caracterizadas pelo alto teor de aminoácidos apolares, conferindo estrutura molecular hidrofóbica, solúveis em álcool para sua extração (SHUKLA \& CHERYAN, 2001).

A concentração de zeína pode corresponder a até $60 \%$ do total de proteínas do grão de milho e é caracterizada de acordo com sua similaridade em massa molecular, solubilidade em solventes e estrutura em quatro subclasses: alfa, beta, gama e delta, sendo geralmente a alfa-zeína presente em maior concentração, podendo também haver variações na composição em diferentes genótipos de milho. Dessa forma, elas podem ser quantificadas e visualizadas pelo processo de eletroforese em gel, método analítico contendo dodecil sulfato de sódio (SDS-PAGE), que determina os diferentes pesos moleculares através das ligações das frações proteicas em função do seu tamanho e forma molecular. A alfazeína caracteriza-se por ser rica em aminoácidos

'Universidade Federal de Santa Maria, Avenida Roraima, nº 1000, Cidade Universitária, Bairro Camobi, 97105-900, Santa Maria, RS, Brasil. E-mail: patricialondero@yahoo.com.br.*Autor para correspondência. 
hidrofóbicos (alanina, leucina e prolina), a betazeína possui altos teores de aminoácidos sulfurados, a gama-zeína constitui-se de resíduos de prolina, e a delta-zeína contém em sua estrutura aminoácidos sulfurados além de prolina e leucina (LARKINS et al., 1993; OLIVEIRA et al., 2004).

O grão de milho é formado por quatro estruturas físicas: endosperma, gérmen, pericarpo (casca) e ponta, estas estruturas diferem em composição química e na disposição interna do grão (Figura 1). O endosperma representa aproximadamente $83 \%$ do peso seco do grão, consiste principalmente de grânulos de amido, em média $88 \%$, sendo classificado em dois tipos: farináceo e vítreo, e concentração de proteínas de reserva, as zeínas $8 \%$. No endosperma vítreo do grão de milho, encontra-se a maior concentração de zeína, em comparação com o endosperma farináceo. As zeínas estão localizadas no exterior dos grânulos de amido, em estruturas circulares, com a região central rica em delta e gama zeína, circundada por alfa zeína (PAES, 2006; ANDERSON \& LAMSAL, 2011).

As zeínas são consideradas de alto grau de polimerização e propriedades isolantes, destacandose sua aplicação na elaboração de filmes para conservação de alimentos altamente perecíveis e microcápsulas na indústria farmacêutica. Filmes são películas formadas a base de polímeros, preparados com adição de um plastificante, aplicadas sobre o produto alimentício. Quando proveniente de fonte natural, é biodegradável em curto período de tempo (VILLADIEGO et al., 2005; FORATO et al., 2013). A formação de novos materiais biodegradáveis substitui o uso de plásticos oriundos de polímeros sintéticos, derivados do petróleo, prejudiciais ao meio ambiente por resistirem à degradação (TAVARES et al., 2012).

Recentes estudos tecnológicos focalizam em novas alternativas para conservação dos alimentos no âmbito de embalagens e filmes com características funcionais, de qualidade e biodegradáveis. Assim, a aplicação da zeína do milho como matéria-prima de fonte natural e renovável é relevante para o avanço dessas pesquisas (ZOLNERKEVIC, 2010; ANDERSON \& LAMSAL, 2011).

Dessa maneira, nesta revisão, serão abordados determinados métodos de extração de proteína zeína, bem como suas aplicações tecnológicas para conservação dos alimentos.

Formas de extração de zeína do milho

Diferentes procedimentos para extração das proteínas dos cereais são relatados na literatura. A extração da zeína do milho pode ocorrer por combinações químicas, com adição ou não de tratamento enzimático, sendo que alguns fatores contribuem para eficiência do processo, como: tipo de solvente, temperatura, $\mathrm{pH}$ e tempo de extração (SHUKLA \& CHERYAN, 2001; CAPOBIANGO et al., 2006).

Os estudos para extração de zeína começaram a partir da farinha de milho, obtida da moagem seca do grão inteiro, com rendimento de 5 a 6\% de extração de zeína. Osborne, em 1891, foi o primeiro a registrar uma patente nos EUA para extração de zeína, a partir da moagem úmida com formação de glúten do milho, esse método, a partir

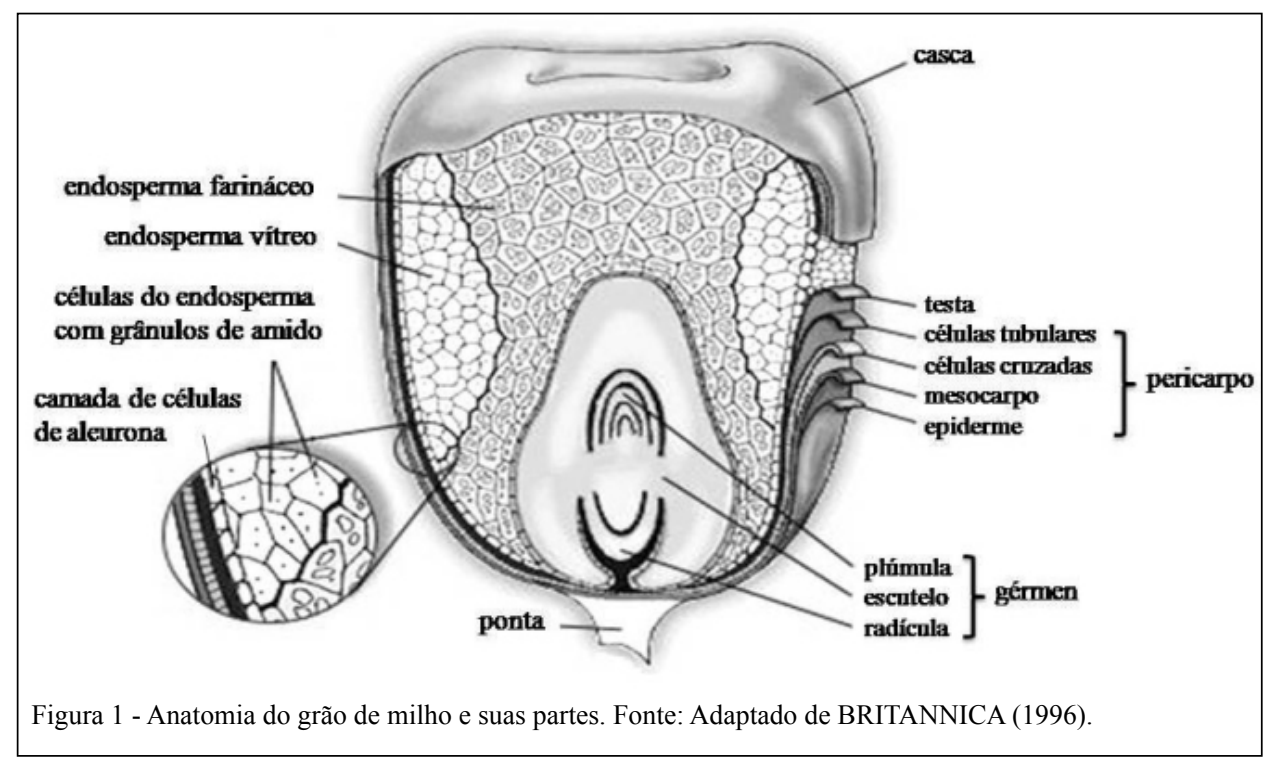

Ciência Rural, v.45, n.2, fev, 2015. 
do glúten, alcançou maior rendimento, de 30 a $40 \%$ de zeína (LAWTON, 2002).

O glúten de milho é a fração separada do gérmen e amido, constituído principalmente de proteínas (60 a 70\% de zeínas), com óleo residual e de alta qualidade para uso industrial, sendo comercialmente produzido para alimentação animal e para extração de zeína (FORATO et al., 2013; GERALDI et al., 2012).

A zeína é constituída de 17 aminoácidos, sendo a maior porcentagem destes apolares. ARGOS et al., (1982) propôs um modelo estrutural em formato de hélice coloidal (união dos aminoácidos polares e apolares), referente à estrutura secundária da proteína zeína. Os aminoácidos apolares estão organizados em estrutura circular, unidos através de três segmentos polares, repetidas em nove hélices sequenciais (Up) e antiparalelas (Dn) em superfície plana molecular (Figura 2a), formando um empilhamento dessas hélices por interações de resíduos de glutamina, parte polar nas extremidades da cadeia (Figura 2b).

O método químico para a extração da zeína a partir do glúten do milho consiste da solubilidade dos aminoácidos apolares de zeína em soluções aquosas alcoolicas, utilizadas como solventes. A extração ocorre geralmente por um determinado período de tempo, o qual é dependente da eficiência da interação do solvente utilizado com a zeína em temperatura entre 50 a $70^{\circ} \mathrm{C}$ e $\mathrm{pH}$ com variações de 6 a 11 para controle da estabilidade em soluções desejadas. O extrato resultante da dissolução é filtrado ou centrifugado e adicionado tolueno, hexano ou benzeno para remoção dos lipídios e pigmentos da zeína. A extração final é o resultado da precipitação por resfriamento em água fria ou em temperaturas de $-10^{\circ} \mathrm{C}$ a $-20^{\circ} \mathrm{C}$ e secagem a vácuo (SHUKLA \& CHERYAN, 2001; LAWTON, 2002).

Diversos solventes podem ser utilizados para a extração da zeína e são divididos em três categorias: primário, secundário e terciário, de acordo com a capacidade de interagir com seus aminoácidos. Solventes primários solubilizam a zeína em concentração $>10 \%$. Solventes secundários solubilizam quando depende de álcool alifático para proporcionar a interação com os aminoácidos não polares e água, para interagir com os aminoácidos polares. Os terciários devem ser uma combinação de álcool alifático, água e outro solvente (LAWTON, 2002; ANDERSON \& LAMSAL, 2011).

Os procedimentos combinados, envolvendo os tratamentos químicos e enzimáticos, referem-se a outras formas de extração de zeína. COOK et al. (1996) desenvolveram um processo de extração de zeína pelo glúten do milho através de um tratamento enzimático. Este método consistiu primeiramente da hidrolisação do amido residual, o

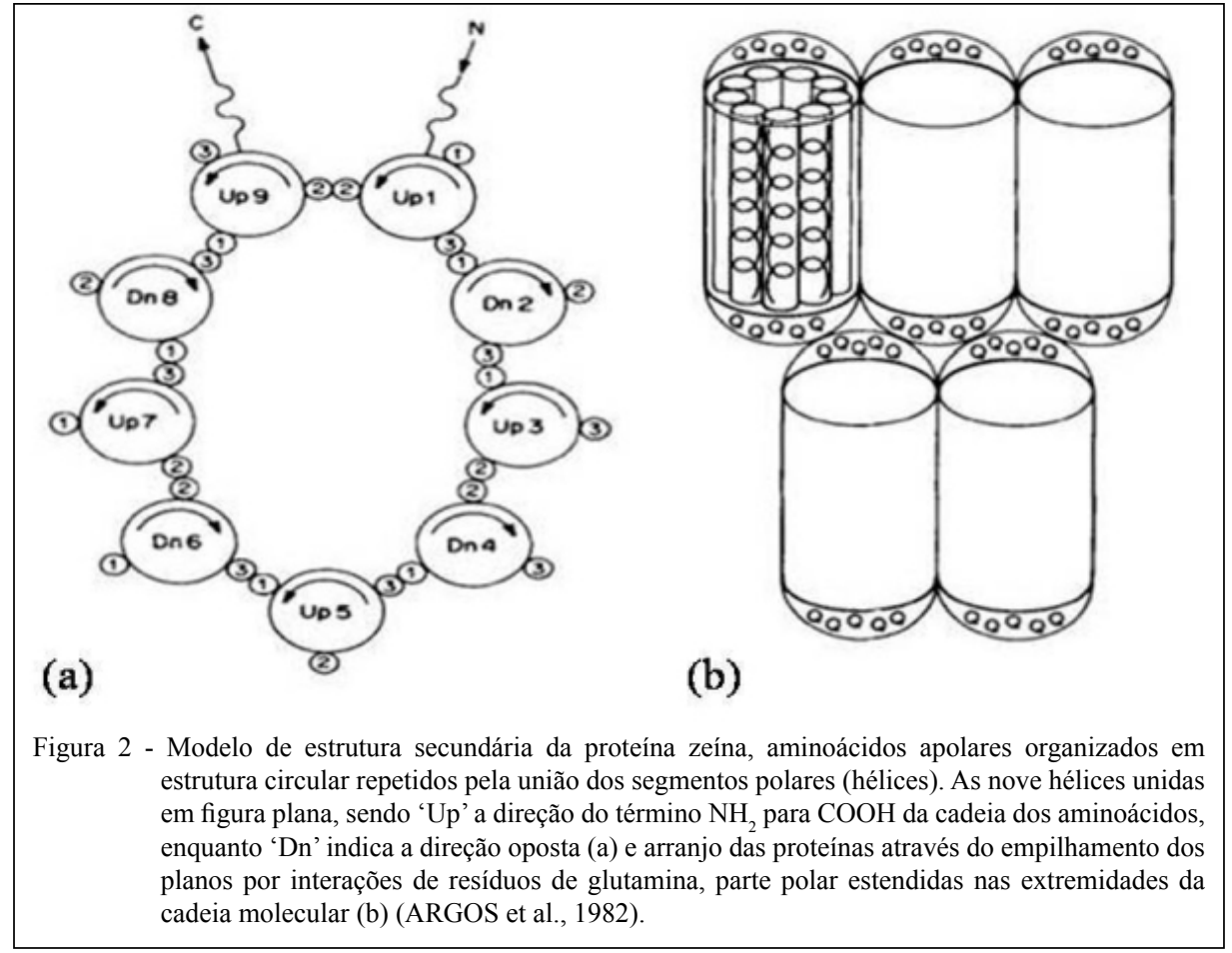

Ciência Rural, v.45, n.2, fev, 2015. 
qual facilita a subsequente remoção de off-flavors e a despigmentação. Para tanto, a amostra é tratada com solução tampão alcalino para a remoção de ácidos graxos e os pigmentos são extraídos com etanol. A característica final da zeína é desejável pela cor branca e por ser inodora. A tecnologia de membranas poliméricas por ultrafiltração e nanofiltração está sendo empregada para a purificação de zeína. Contudo, existem fatores que causam a degradação da membrana e rejeição da zeína. Dessa forma, cuidados referentes a escolha do material da membrana, pressão aplicada, concentrações e quantidades de solventes devem ser considerados. Recentemente, o uso da cromatografia revelou-se promissora na purificação da zeína (>90\%) e separação de xantofilas (SHUKLA \& CHERYAN, 2002; CHERYAN et al., 2012).

Outro procedimento de extração, por método enzimático, foi relatado por CAPOBIANGO et al. (2006), em fubá de milho, avaliando a eficiência de extração pela enzima empregada de uma protease bacteriana de Bacillus liccheniformis. Entretanto, os métodos enzimáticos apresentaram rendimentos inferiores, comparados aos métodos químicos, provavelmente devido às interações com outros constituintes, como lipídios e carboidratos.

Atualmente, a metodologia empregada para extração de zeína no Brasil é descrita por FORATO et al. (2013). De acordo com estes autores, a zeína obtida a partir do glúten do milho é tratada inicialmente com hexano em extrator Soxlhet por 24 horas para a remoção de gorduras; seguida de agitação em solução de cloreto de sódio por 6 horas (para remoção das outras proteínas presentes no grão: albuminas, glutelina e globulinas). Por fim, as zeínas são obtidas com solvente etanol a $70 \%$ por 24 horas e precipitadas em evaporação, seguida por liofilização.

A evolução dos processos, devido às constantes pesquisas, contribuiu para a diminuição de custos e melhores controles de extração referentes à preparação do milho, diferenças do tipo de moagem e variações de temperaturas e $\mathrm{pH}$. A zeína comercial é composta de alfa-zeína e tende a ser de alta qualidade e pureza, podendo ser obtida dos produtos industrializados dos grãos de milho ou por moagem úmida, com formação de glúten, mas os rendimentos ainda são considerados baixos em ambos métodos, inferiores a $50 \%$, havendo a necessidade de contínua pesquisa para novos tipos de tratamentos e solventes (LAWTON, 2002; ANDERSON \& LAMSAL, 2011b; FORATO et al., 2013; GERALDI et al., 2012). Um método de extração empregado comercialmente é referente a Carter e Reck desde 1970 (Figura 3), usando como solvente $88 \%$ de isopropanol (IPA) em solução aquosa.

Aplicações tecnológicas para conservação dos alimentos

Novas técnicas de armazenamento e desenvolvimento de embalagens estão sendo pesquisadas para atenuar perdas pós-colheita e o desperdício de alimentos, os quais geram prejuízo econômico de 750 bilhões de dólares anuais, além de afetar o meio ambiente com a emissão de gases causadores do efeito estufa (PARISI et al., 2012; FAO, 2013). Avaliando alternativas sustentáveis, revestimentos de polímeros naturais aplicados sobre os alimentos, entre eles proteínas, lipídios e polissacarídeos, estão sendo estudados, a fim de ampliar o mercado de embalagens biodegradáveis (DURANGO et al., 2011).

A zeína foi utilizada em grande quantidade como matéria-prima para diversos produtos até o surgimento de polímeros sintéticos, de baixo valor econômico, provenientes de fontes não renováveis a partir de 1950 (ANDERSON \& LAMSAL, 2011).

A variedade e o consumismo de produtos industrializados com polímeros sintéticos nas últimas décadas aumentaram a quantidade de descarte destes materiais, principalmente no que se refere ao uso de embalagens. Esses polímeros apresentam longo tempo de degradação, devido a sua alta massa molecular, levando séculos para decomporem-se. A coleta seletiva e os processos de reciclagem tornaram-se alternativas para diminuir o acúmulo destes materiais, todavia esses sistemas não são acessíveis a toda população, a qual carece de incentivo e informação por parte do governo e de empresas relacionadas à produção dos polímeros sintéticos (REBELLO, 2009; NETO et al., 2011).

A proteína zeína apresenta capacidade de formação de filmes semelhantes ao plástico, devido ao seu alto grau de polimerização e caráter hidrofóbico, os quais mantêm a integridade dos alimentos, pois potencializam barreiras à umidade, transporte de oxigênio, dióxido de carbono e demais compostos voláteis (LAWTON, 2002; FORATO et al., 2013). Sua aplicação estende-se na preparação controlada de fármacos em microcápsulas, que permitem a liberação da droga somente ao alcançar o intestino, protegendo da acidez do estômago (GOMEZ-ESTACA et al., 2012).

O desafio dos pesquisadores é encontrar aplicações que permitam o consumo em maior proporção de filmes para embalagens e biomateriais para outros fins, resultando na redução de seu custo, 


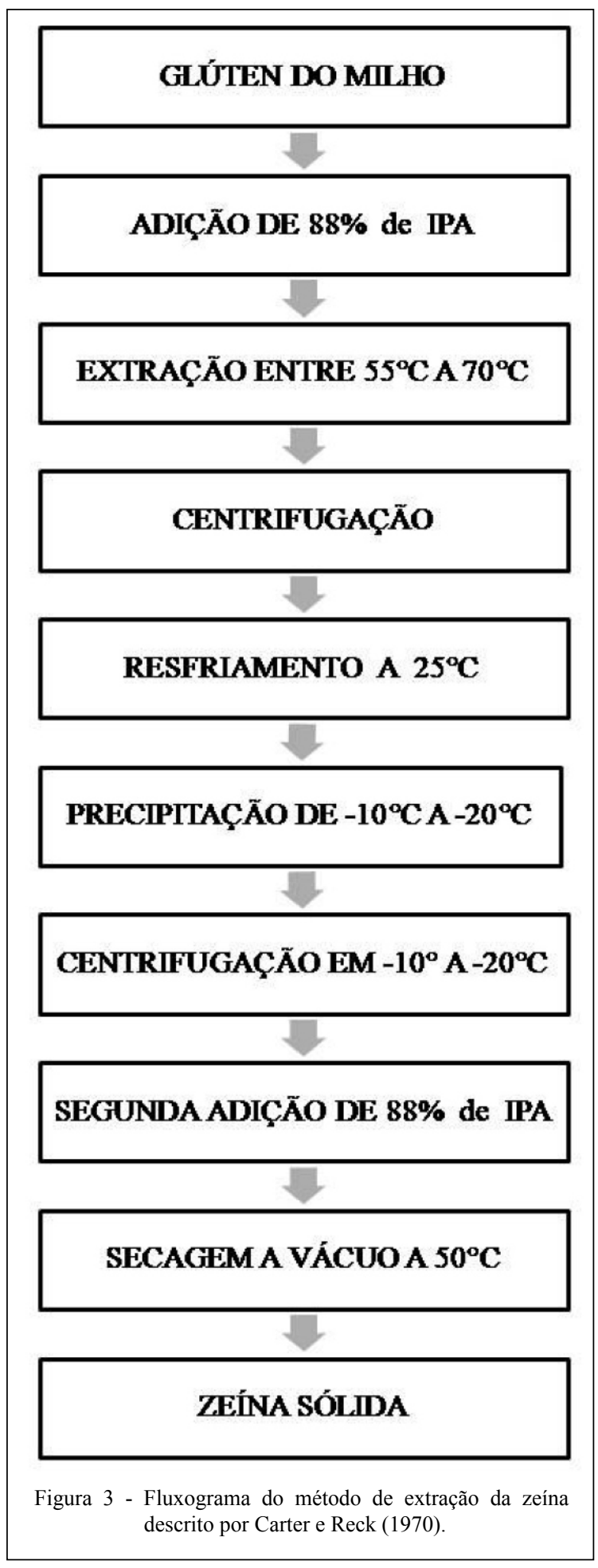

competição econômica no mercado e substituição de plásticos de filmes de polímeros sintéticos convencionais, derivados de fontes petrolíferas (NETO et al., 2011).
A biodegradação dos filmes de fontes naturais é realizada em curto período de tempo e envolve duas etapas: a despolimerização e a degradação por reações catalisadas por enzimas e por micro-organismos em compostos naturais, para dióxido de carbono, água e outros (VILLADIEGO et al., 2005; ABICOM, 2012).

A elaboração do filme envolve diversos componentes: agente formador de filme (macromoléculas, polímeros de alto peso molecular), solvente (água, etanol, água/etanol, entre outros), plastificante (glicerol e sorbitol), e agente ajustador de $\mathrm{pH}$ (como ácido acético e hidróxido de amônia) (BATISTA, 2004).

A utilização da zeína como material básico para a finalidade de produção de embalagens biodegradáveis contribui para a diversificação do mercado na utilização da fração proteica do milho, agregando outro valor econômico e social nas indústrias moageiras e para os produtores do grão.

O polímero zeína é frágil, havendo a necessidade da adição de plastificantes para a melhoria das propriedades mecânicas dos filmes. Colaborando com sua potencialidade, a adição de nanopartículas aos filmes exibe propriedades superiores, como maior resistência, maior estabilidade térmica e oxidativa, melhor barreira a gases e à água (TAVARES et al., 2012). A incorporação de ácidos graxos, a exemplo do ácido oleico, como plastificante, produz filmes flexíveis, homogêneos, transparentes e de boa aceitação (XU et al., 2012; FORATO et al., 2013). Resultados desta aplicação apresentaram diminuição da perda de massa em maçãs, devido à menor perda de água e trocas gasosas (SCRAMIN et al., 2007). Em peras armazenadas por um período de 12 dias à temperatura ambiente, a formulação a base de zeína com baixas concentrações de ácido oleico $(0,25 \%)$ influenciou positivamente nas propriedades mecânicas como plastificante, obtendo-se o melhor resultado para a conservação da fruta. Concentrações maiores de ácido oleico ao filme resultam em maior afinidade deste com a água e redução na proteção da fruta (SCRAMIN et al., 2011).

BAI et al. (2003) desenvolveram uma formulação de revestimento brilhoso com zeína aplicado em maçã semelhante à goma comercial, resultando em shelf life prolongado em comparação com amostras não revestidas e de frutas revestidas com cera de carnaúba.

Aumento de shelf life pela inibição microbiana e controle da perda de peso foram verificados em morangos armazenados durante 21 dias com revestimentos de zeína, glúten de 
trigo e quitosana. Para os atributos relacionados à conservação de firmeza e valor nutritivo ao fruto, a zeína apresentou o melhor resultado (REHMAN et al., 2010). Filme de zeína adicionados de agente antimicrobiano e antioxidades conservaram a qualidade de frutas secas de damasco (Prunus Armenica L.) analisadas durante 10 meses (BAYSAL et al., 2010).

Aplicação de revestimentos de zeína em manga e tomate mostraram efeitos benéficos no retardamento do processo de amadurecimento, através da diminuição da taxa de respiração e produção de etileno, postergando a mudança de cor e perda de peso, mantendo a firmeza dos frutos durante o armazenamento (PARK, 1999; HOA et al., 2002; ZAPATA et al., 2008).

No estudo de FORATO et al. (2008), o melhor resultado para a conservação da noz macadâmia foi obtido com soluções de zeínas adicionado de $20 \%$ de propilenoglicol, como plastificante, cuja formulação reduziu a oxidação de seus ácidos graxos insaturados que ocasionam alterações do seu valor nutritivo e dos aspectos sensoriais.

No entanto, o comportamento dos filmes pode ter ação diferenciada para os distintos frutos, de classificação climatérico ou não, ou em função do tipo de processamento, da temperatura e umidade local de armazenamento (VILLADIEGO et al., 2005; ASSIS et al., 2009).

A adição de nisina e lisozima em filmes de zeína de milho ou proteína de soja auxiliaram no controle do desenvolvimento de Escherichia coli, Lactobacillus plantarum e Listeria monocytogenes em produtos cárneos (HOFFMAN et al., 2001). Os filmes contribuíram também para reduzir a oxidação lipídica e off-flavors em embalagens de costeletas de carne suína pré-cozidas, prolongando o shelf life durante o armazenamento (CUTTER, 2006). Recentemente, o sucesso da inibição da oxidação lipídica e a estabilidade de cor foram efetivos através da aplicação de filme de zeína laminada similar ao plástico com compostos fenólicos naturais para embalagem de carne fresca moída (PARK et al., 2012).

A aplicação da zeína em filmes foi eficiente na redução de absorção de óleo em batatas fritas, melhorando a qualidade do produto final, devido às propriedades funcionais da macromolécula zeína ser hidrofóbica e de baixa permeabilidade ao vapor de água (MALLIKARJUNAN et al., 1997). A propriedade de barreira ao oxigênio em filme a base de zeína e proteína de soja resultou em uma embalagem na qual reduziu o ranço oxidativo do azeite de oliva para acompanhar macarrão instantâneo, quando comparado ao produto embalado ao filme de forma convencional (CHO et al., 2010).

Pode-se constatar que existem inúmeros estudos realizados com filmes a base de zeína para diferentes alimentos, obtendo-se sucesso na sua conservação, porém carecem de ampliação de sua utilização a nível industrial e aceitação pelos consumidores.

\section{CONCLUSÃO}

As zeínas possuem alto grau de polimerização e capacidade de formação de filmes para conservação de alimentos, devido às propriedades de barreira à umidade, dióxido de carbono e ao oxigênio para reduzir o ranço oxidativo, manter a estabilidade de massa e valor nutritivo. A extensa pesquisa em extração por métodos químicos ou combinados a partir do glúten do milho propõe maiores rendimentos e a aplicação tecnológica substitui o uso de plásticos oriundos de polímeros sintéticos por novos materiais biodegradáveis, contribuindo para a diminuição de perdas pós-colheita, shelf life prolongado dos produtos e a inserção da cultura do milho em novos mercados.

\section{REFERÊNCIAS}

ABICOM (ASSOCIAÇÃO BRASILEIRA DE POLÍMEROS BIODEGRADÁVEIS E COMPOSTÁVEIS). Plásticos biodegradáveis - O que são?, 2012. Disponível em: <http:// abicomweb.org.br/artigos/16/>. Acesso em: 24 mar. 2014.

ANDERSON, T.J.; LAMSAL, B.P. Zein extraction from corn, corn products, and coproducts and modifications for various applications: a review. Cereal Chemistry, v.88, n.2, p.159-173, 2011. Disponível em: <http://cerealchemistry.aaccnet.org/doi/ abs/10.1094/CCHEM-06-10-0091>. Acesso em: 20 mar. 2014. doi: 10.1094/CCHEM-06-10-0091.

ANDERSON, T.J.; LAMSAL, B.P. Development of new method for extraction of $\alpha$-Zein from corn gluten meal using different solvents. Cereal chemistry, v.88, n.4, p.356-362, 2011. Disponível em: $<$ http:// cerealchemistry.aaccnet.org/doi/abs/10.1094/CCHEM-08-10-0117>. Acesso em: 20 mar. 2014. doi: 10.1094/CCHEM-08-10-0117.

ARGOS, P. et al. A structural model for maize zein proteins. Journal of Biological Chemistry, v.257, n. 17, p.9984-9990, 1982. Disponível em: <http://www.jbc.org/content/257/17/9984.short>. Acesso em: 23 mar. 2014.

ASSIS, O. et al. O uso de biopolímeros como revestimentos comestíveis protetores para conservação de frutas in natura $\mathrm{e}$ minimamente processadas. Embrapa Instrumentação Agropecuária. Boletim de Pesquisa e Desenvolvimento, São Carlos, n.29, nov. 2009. Disponível em: <www.cnpdia.embrapa.br $>$. Acesso em: 26 mar. 2014. 
BAI, J. et al. Formulation of zein coatings for apples (Malus domestica Borkh). Postharvest Biology and Technology, v.28, p.259-268, 2003. Disponível em: <http://www.sciencedirect.com/ science/article/pii/S0925521402001825>. Acesso em: 23 mar. 2014. doi: 10.1016/S0925-5214(02)00182-5.

BATISTA, J.A. Desenvolvimento, caracterização e aplicações de biofilmes a base de pectina, gelatina e ácidos graxos em bananas e sementes de brócolis. 2004. 141f. Dissertação (Mestrado Alimentos e Nutrição) - Curso de Pós-graduação em Alimentos e Nutrição, Universidade Estadual de Campinas, SP.

BAYSAL, T. et al. The effect of corn zein edible film coating on intermediate moisture apricot (prunus armenica 1.) Quality. GIDA, v.35, n.4, p.245-249, 2010. Disponível em: <http://www. gidadernegi.org/TR/Genel/dg.ashx?DIL=1\&BELGEANAH=5372 \&DOSYAISIM=703350402.pdf>. Acesso em: 23 mar. 2014.

BRITANNICA, Encyclopaedia Britannica, Inc 1996. The outer layers and internal structures of a kernel of corn. Disponível em: <http://global.britannica.com/EBchecked/topic/103350/cerealprocessing > . Acesso em: 10 ago. 2013. Online.

CAPOBIANGO, M. et al. Extração química e enzimática das proteínas do fubá de milho. Ciência e Tecnologia dos Alimentos, Campinas, v.26, n.4, p.884-890, 2006. Disponível em: <http:// www.scielo.br/pdf/cta/v26n4/26.pdf>. Acesso em: 23 mar. 2014.

CARTER, R.; RECK, D.R. Low temperature solvent extraction process for producing high purity zein. Nutrilite Products Inc. (California, EUA). US 3535305, 12 Fev. 1968, 20 Out. 1970.

CHERYAN, M. et al. Method and System for Production of Zein and/or Xanthophylls using Chromatography. The board of trustess of the (Urbana).US 8236929 B2, 8 Maio 2007, 7 Ago. 2012.

CHO, S.Y. et al. Edible oxygen barrier bilayer film pouches from corn zein and soy protein isolate for olive oil packaging. Food Science and Technology, v.43, n.8, p.1234-1239, 2010. Disponível em: < http://www.sciencedirect.com/science/article/pii/ S0023643810001143>. Acesso em: 17 mar. 2014. doi: 10.1016/j. 1wt.2010.03.014

COOK, R. et al. Purification of Zein from corn gluten meal. Opta Food Ingredients (United States) US 5580959. 10 Mar. 1995, 3 Dez. 1996.

CUTTER, C. Opportunities for bio based packaging technologies to improve the quality and safety of fresh and further processed muscle foods. Meat Science, v.74, p.131-142, 2006. Disponível em: <http:// www.sciencedirect.com/science/article/pii/S0309174006001379>. Acesso em: 10 mar. 2014. doi: 10.1016/j.meatsci.2006.04.023.

DURANGO, A.M. et al. Filmes y revestimientos comestibles como empaques activos biodegradables en la conservación de alimentos. Biotecnología en el Sector Agropecuario y Agroindustrial, v.9, n.1, p.122-128, 2011. Disponível em: <http://www.scielo.org.co/ pdf/bsaa/v9n1/v9n1a14.pdf >. Acesso em: 22 mar. 2014.

FAO. Organização das Nações Unidas para Alimentação e Agricultura, 2009. Desperdício de alimentos tem consequências no clima, na água, na terra e na biodiversidade. Disponível em: $<$ https://www.fao.org.br/daccatb.asp>. Acesso em: 15 mar. 2014.

FORATO, L.A. et al. Avaliação da ação anti-oxidante de coberturas a base da proteína Z19 do Milho BR451 em noz macadâmia. Circular técnico, São Carlos, n.24, nov. 2008. Disponível em:
$<$ http://www.infoteca.cnptia.embrapa.br/handle/doc/31724>. Acesso em: 23 mar. 2014

FORATO, L.A. et al. Propriedades mecânicas e molhabilidade de filmes de zeínas extraídas de glúten de milho. Polímeros, v.23, n.1, p.42-48, 2013. Disponível em: < http://www.scielo.br/pdf/po/ v23n1/aop 0995.pdf>. doi: 10.1590/S0104-14282012005000075. Acesso em: 12 mar. 2014.

GERALDI, C.A.Q. et al. Análise econômico-financeira de um novo processo de produção de derivados de milho. ENGEVISTA, v.14, n.2, p.185-195, 2012. Disponível em: <http://www.uff.br/ engevista/seer/index.php/engevista/article/viewArticle/408>. Acesso em: 10 maio 2013.

GOMEZ-ESTACA, J. et al. Formation of zein nanoparticles by electrohydrodynamic atomization: effect of the main processing variables and suitability for encapsulating the food coloring and active ingredient curcumin. Food Hydrocolloids, v.28, p.82-91, 2012. Disponível em: <http://www.sciencedirect.com/science/ article/pii/S0268005X11003122>. Acesso em: 12 mar. 2014. doi: 10.1016/j.foodhyd.2011.11.013.

HOA, T.T. et al. Effect of different coating treatments on the quality of mango fruit. Journal of Food Quality, v.25, n.6, p.471-486, 2002. Disponível em: <http://onlinelibrary.wiley.com/ doi/10.1111/j.1745-4557.2002.tb01041.x/abstract>. Acesso em: 17 mar. 2014. doi: 10.1111/j.1745-4557.2002.tb01041.x.

HOFFMAN, K. et al. Antimicrobial effects of corn zein films impregnated with nisin, lauric acid, and EDTA. Journal of Food Protection, v.64, n.6, p.885-889, 2001. Disponível em: $<\mathrm{http}: / /$ www.ncbi.nlm.nih.gov/pubmed/11403145>. Acesso em: 22 mar. 2014.

LARKINS, B.A. et al. Modification of maize-seed-protein quality. American Journal of Clinical Nutrition, v.58, n.2, p.264s-269s, 1993. Disponível em: <http://www.ncbi.nlm.nih.gov/ pubmed/8328398>. Acesso em: 22 mar. 2014.

LAWTON, J.W. Zein: a history of processing and use. Review. Cereal Chemistry, v.79, n.1, p.1-18, 2002. Disponível em: $<$ http://www.prairie-gold.com/zein_background.pdf $>$. Acesso em: 23 mar. 2014.

MALLIKARJUNAN et al. Edible coatings for deep-fat frying of starchy products. Food Science and Technology, v.30, n.7, p.709-714, 1997. Disponível em: <http://www.sciencedirect.com/ science/article/pii/S0023643897902632>. Acesso em: 17 mar. 2014. doi: $10.1006 /$ fstl.1997.0263.

MIRANDA, R.A. et al. Mercado e comercialização. Embrapa Milho e Sorgo, 2012. 2014. Online. Disponível em: <http:// www.cnpms.embrapa.br/publicacoes/milho_8_ed/mercado.htm $>$. Acesso em: 24 mar.

NETO, H.H.P. et al. Sacolas plásticas: consumo inconsciente. Perspectivas online: Ciências biológicas e da saúde, v.3, n. 1, p.5070, 2011. Disponível em: <http://www.seer.perspectivasonline. com.br/index.php/index/index>. Acesso em: 22 mar. 2014.

OLIVEIRA, J.P. et al. Teor de proteína no grão em populações de milho de alta qualidade protéica e seus cruzamentos. Pesquisa Agropecuária Tropical, v.34, n.1, p.45-51, 2004. Disponivel em: $<$ http://www.revistas.ufg.br/index.php/pat/article/view/2341>. Acesso em: 23 mar. 2014 
OSBORNE, T. Process of extracting zein. United States Patent Office (New Haven). US 456773. 23 Abr. 1891, 28 Jul. 1891.

PAES, M.C.D. Aspectos físicos, químicos e tecnológicos do grão de milho. nutrição humana e ciência dos alimentos embrapa milho e sorgo. Sete Lagoas, Circular técnica 75, dez. 2006. Disponível em: <http://www.cnpms.embrapa.br/publicacoes/ publica/2006/circular/Circ_75.pdf>. Acesso em: 23 mar. 2014.

PARISI, M.C.M. et al. Perdas Pós-colheitas: um gargalo na produção de alimentos. Pesquisa e Tecnologia, v.9, n.2, 2012. Disponível em: $\quad<$ http://www.aptaregional.sp.gov.br/index.php?option=com docman $\&$ task $=$ doc_view $\&$ gid $=1341 \&$ Itemid $=284>$. Acesso em: 24 mar. 2014.

PARK, H.J. Development of advanced edible coatings for fruits. Trends in Food Science \& Technology, v.10, p.254-260, 1999 Disponível em: <http://www.sciencedirect.com/science/article/pii/ S0924224400000030>. Acesso em: 15 mar. 2013. doi: 10.1016/ S0924-2244(00)00003-0.

PARK, H.Y. et al. Development of antioxidant packaging material by applying corn-zein to LLDPE film in combination with phenolic compounds. Journal of Food Science, v.77, n.10, p.E273-E279, 2012. Disponível em: <http://onlinelibrary.wiley.com/doi/10.1111/ j.1750-3841.2012.02906.x/stract?deniedAccessCustomisedMessa ge $=\&$ userIsAuthenticated $=$ false $>$. Acesso em: 12 mar. 2014. doi: 10.1111/j.1750-3841.2012.02906.x.

REBELLO, F.F.P. Novas tecnologias aplicadas às embalagens de alimentos. Revisão. Revista Agrogeoambiental, Dez. 2009. Disponível em: <http://joomla3.ifsuldeminas.edu.br/ ojs/index.php/ Agrogeoambiental/article/view/225>. Acesso em: 23 mar. 2014.

REHMAN, M.U. et al. Effects of carbohydrate and protein based edible coatings on quality of strawberry during storage. SAARC Journal of Agriculture, v.8, n.2, p.01-10, 2010. Disponível em: $<$ http://www.cabdirect.org/abstracts/20113350666.html;jsessioni $\mathrm{d}=$ EDDFFB3C4DB2AF5FD2C7A8ED3B47C717>. Acesso em: 20 mar. 2014.

SCRAMIN, J.A. et al. Caracterização da ação protetora de filmes à base de zeínas e ácido oléico aplicados em maçãs in natura. São Carlos: Embrapa Instrumentação Agropecuária, 2007. Circular técnica, 37. Disponível em: $<$ http://www.infoteca. cnptia.embrapa.br/handle/doc/28095>. Acesso em: 23 mar. 2014.

SCRAMIN, J.A. et al. Characterisation of zein-oleic acid films and applications in fruit coating. International Journal of
Food Science and Technology, v.46, n.10, p.2145-2152, 2011. Disponível em: <http://onlinelibrary.wiley.com/doi/10.1111/ j.1365-2621.2011.02729.x/stract?deniedAccessCustomisedMes sage $=\&$ userIsAuthenticated $=$ false $>$. Acesso em: 12 mar. 2014. doi: 10.1111/j.1365-2621.2011.02729.x.

SHUKLA, R.; CHERYAN, M. Zein: the industrial protein from corn. Elsevier, Industrial Crops and Products, v.13, p.171-192, 2001. Disponível em: <http://www.sciencedirect.com/science/ article/pii/S0926669000000649>. Acesso em: 20 mar. 2014. doi: 10.1016/S0926-6690(00)00064-9.

SHUKLA, R.; CHERYAN, M. Performance of ultrafiltration membranes in ethanol-water solutions: effect of membrane conditioning. Journal of Membrane Science, v.198, p.75-85, 2002. Disponível em: <http://www.sciencedirect.com/science/ article/pii/S037673880100638X>. Acesso em: 20 mar. 2014. doi: 10.1016/S0376-7388(01)00638-X.

TAVARES, L. et al. Effect of modified clays on the structure and functional properties of biofilms produced with zein. Ciência e Tecnologia de Alimentos, Campinas, v.32, n.2, p.314-322, 2012. Disponível em: <http://www.scielo.br/scielo.php?script=sci_artte xt\&pid=S0101-20612012000200017> . Acesso em: 20 mar. 2014.

VILLADIEGO, A.M.D. et al. Filmes e revestimentos comestíveis na conservação de produtos alimentícios. Revista Ceres, v.52, n.300, p.221-244, 2005. Disponível em: <http://www.ceres.ufv.br/ ceres/revistas/V52N300P01805.pdf>. Acesso em: 26 mar. 2014.

XU, H. et al. Synergistic effect of oleic acid and glycerol on zein film plasticization. Journal of Agricultural and Food Chemistry, v.20, n.40, p.10075-10081, 2012. Disponível em: <http://pubs.acs. org/doi/abs/10.1021/jf302940j>. Acesso em: 12 mar. 2014. doi: 10.1021/jf302940j.

ZAPATA, P.J. et al. Use of alginate or zein as edible coatings to delay postharvest ripening process and to maintain tomato (Solanum lycopersicon Mill) quality. Journal of Science of Food and Agriculture, v.88, n.7, p.1287-1293, 2008. Disponível em: $<$ http://onlinelibrary.wiley.com/doi/10.1002/jsfa.3220/stract?de niedAccessCustomisedMessage $=\&$ userIsAuthenticated $=$ false $>$. Acesso em: 10 mar. 2014. doi: 10.1002/jsfa.3220.

ZOLNERKEVIC, I. Plástico de comer. Revista Unespciência, v.42, out. 2010. Disponível em: $<$ http://www.unesp.br/aci/revista/ ed13/quem-diria>. Acesso em: 16 nov. 2012. 